\title{
Intelligent Educational Ecosystems
}

\author{
Denis OBOLENSKY \\ Undergraduate Student \\ Information Technologies and Computer Systems Department \\ Institute of Information Technologies and Management in Technical Systems \\ Sevastopol State University \\ 33, Universitetskaya str., Sevastopol, 299053, Russia \\ +7 (978) 841-34-75 \\ denismaster@outlook.com \\ Victoria SHEVCHENKO \\ Scientific Advisor \\ Ph.D. (in Technical Science) \\ Associate Professor \\ Information Technologies and Computer Systems Department, \\ Institute of Information Technologies and Management in Technical Systems, \\ Sevastopol State University, \\ 33, Universitetskaya str., Sevastopol, 299053, Russia \\ VIShevchenko@sevsu.ru
}

\begin{abstract}
In this article, the author explores modern approaches used in distance education, defines the problems of distance learning, such as the problem of feedback, relevance, the search for the necessary courses, as well as the importance of courses, taking into account the competency-based paradigm of knowledge acquisition. During the research, the author examines ideas that can improve feedback and the quality of knowledge gained, personalize the subjects studied. The author suggests also to use job and $\mathrm{CV}$ datasets to find important statistic data required for these improvements. The idea of individual educational paths is being studied, which are formed depending on individual skills, student cognitive abilities as well as his goals. The conceptual model of knowledge in the form of an overlay network is considered. The analysis of current solutions that can be used to build individual educational trajectories is carried out, in particular, a differentiated
\end{abstract}


approach, the decision tree method, probabilistic and graph approaches were studied, their pros and cons were determined. As a result, the concept of an intellectual educational ecosystem is being created. The structure, metrics, components of the educational ecosystem are described. Based on this concept, the author planned to develop a DSS to build personal recommendations in distance education using modern methods of machine learning and artificial intelligence.

Keywords: individual educational path; educational ecosystem; personalization; distance education.

\section{Introduction}

In the modern world, information technologies are increasingly used in various areas of our society. One of the most interesting and, of course, important areas is education. Learning around the world, learning new areas of knowledge without leaving home. It attracts more and more people.

Important features of distance learning are accessibility and scalability. An unlimited number of people can study the course materials at any convenient time and place. There are great opportunities for collecting analytics and information (Hsu, 2008).

However, online learning also has its disadvantages. In addition to the lack of motivation and low statistics on the course, there is a lack of individualization of the course materials for each student. Subjects of material are strictly defined by course creators and may not be adapted for the individual cognitive abilities of students.

Many courses are created for a big amount of people all around the globe. Thus, it is becoming increasingly difficult to obtain any kind of feedback, to determine the factors that affect learning, to evaluate the qualifications of teachers (Kravets, Zaslavskaya, 2012).

Even though not everyone can say what they want to learn now or in the nearest future, therefore it is impossible to accurately determine the relevance of the course for students.

The structure of the learning model has also recently changed in the direction of the competencebased knowledge paradigm (Kravets, Zaslavskaya, 2012; Serebrovsky, Tkachenko, Tkachenko, 2013). This method aims to develop the skills required in companies. Unfortunately, a sufficiently large number of distance learning courses are not adapted to the skill-based model.

Thus, it becomes inappropriate to prepare a single predefined course program when we need to take into account the skills and abilities of each student. To solve that task a system of "individual educational path of learning" is proposed. 
The main ideas in the root of the individual educational paths (IEP), also called as Learning Paths, are the concepts of adaptive, modular and personalized education. Adaptability implies the presence of feedback between the student and the teacher, as well as a motivation system. The modular presentation of training materials allows you to cluster knowledge and practical experiences on the skills developed. Personalization allows you to create an individual learning sequence, as well as to use the most suitable elements in the best way to consume (Serebrovsky, Tkachenko, Tkachenko, 2013).

\section{Methods}

To find out the pros and cons of the usage of individual education paths in distance education we need to explore scientific works in this area of research.

The knowledge model, according to the work of V. Lyubchenko (Lyubchenko, Shinkaryuk, 2011), can be represented as an overlay model in the form of a network of concepts. These concepts are connected according to the principle of a semantic network or graph. A connection between this model and the skill paradigm allows the generation of subgraphs of knowledge graph corresponding to different skills in numerous ways. It also allows you to create, enhance, develop knowledge sets that are within the skill, as well as use them to build an individual educational path. An example of a concept model is presented in Figure 1. 


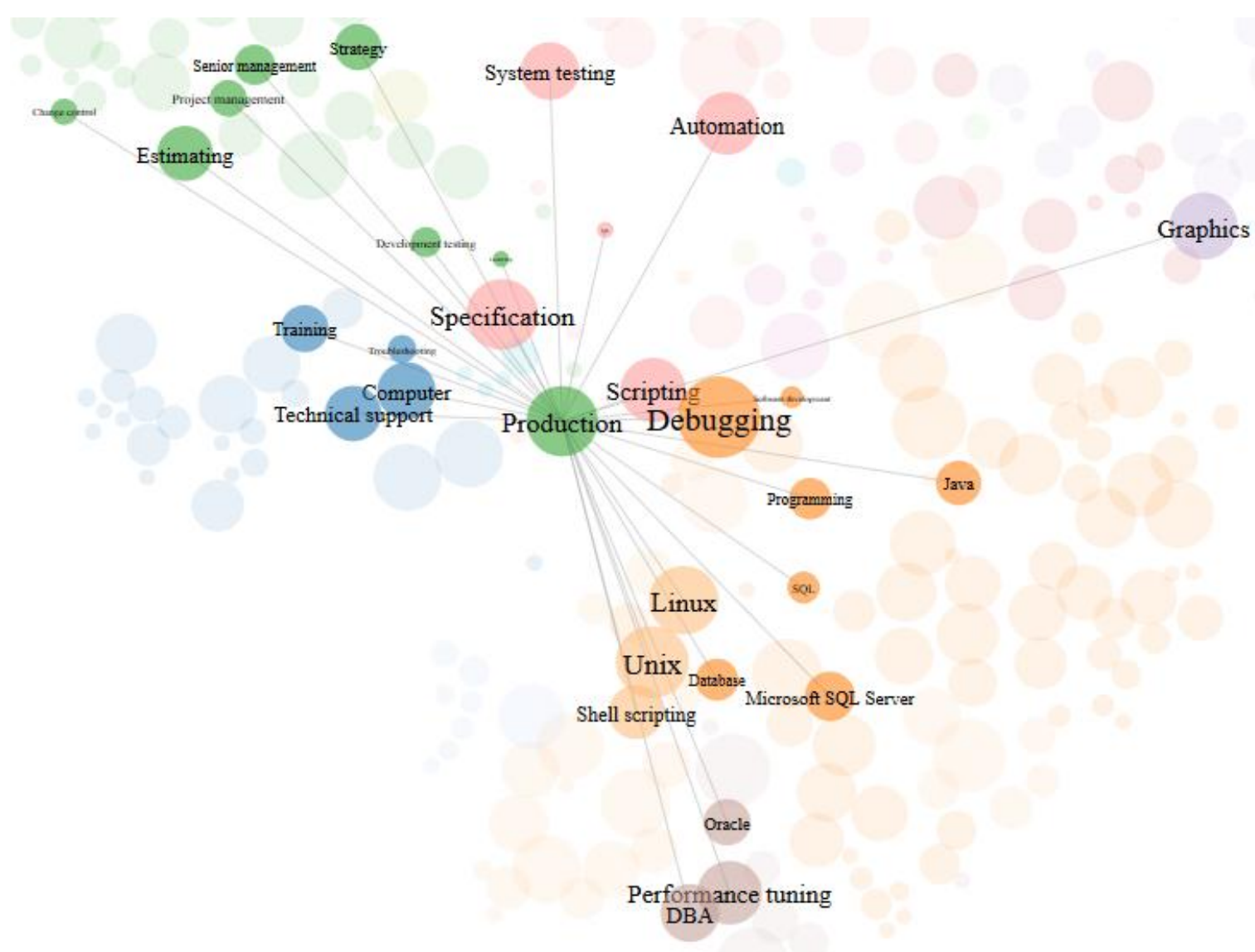

\section{Figure 1. An example of a concept graph model}

The simplest way to create individual paths is differentiated learning. The course creators and teachers work together to draw up several predefined development paths, and the student can choose the most suitable for him. Another way to form such an individual path is to cluster groups of students based on various metrics (Belyaev, Kravets, 2011). It is proposed to use a linear convolution algorithm of parameters in the form of an integral additive goal function (Belyaev, Kravets, 2011), presented in the formula (1), as a calculation of the current target level of training.

$$
\Omega=\sum_{k=1}^{K} a_{k} s_{k}(t),
$$

where $K$ - the total number of metrics, $a_{k}$ - the weight coefficient value, $s_{k}(t)-$ a value of $k$-th metric at time $t$.

This approach is the easiest to implement and is also very similar to the traditional, linear learning mode. An example of the implementation of this approach is presented in Figure 2. 


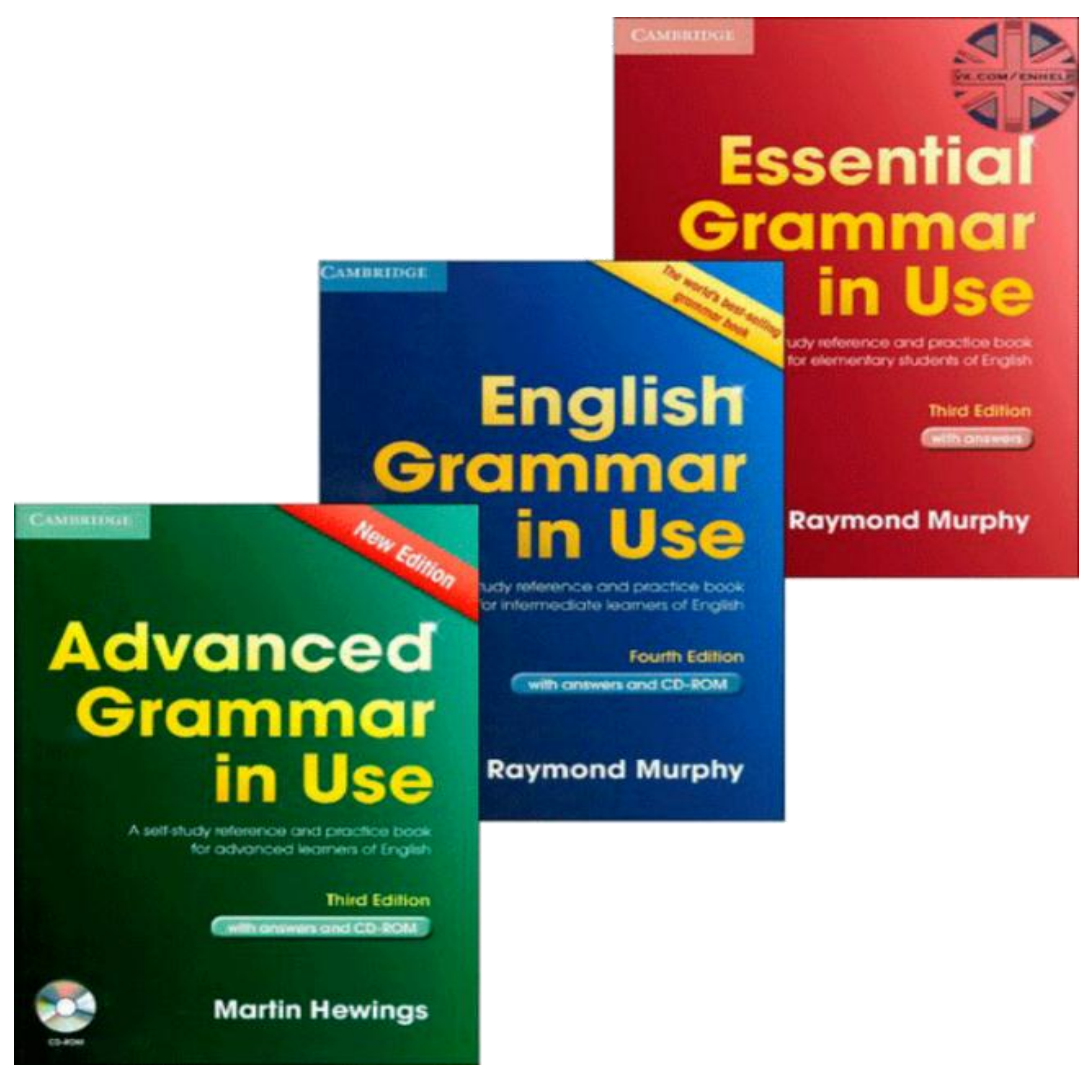

Figure 2. An example of differentiated learning - different levels of English books (Hsu, 2008)

The decision tree method (Lin, Yeh, Hung, Chang, 2013), proposed by Lin C., allows you to direct the students along one path or another, depending on the results of their knowledge level evaluation. The course creators must propose a methodology for assessing student's knowledge level, the order of the tests and the decision tree. An individual educational path is then formed dynamically, based on the results of the tests. The evaluation process plays an important role in this method.

A. Afanasyev (Afanasyev, Voight, 2013) proposes the use of fuzzy Kohonen maps for assessing students' knowledge level and skills. E. Soldatkin (Soldatkin, 2013) proposes an automated method for generating test tasks based on the composition of fuzzy sets. Chen C. (Chen, Duh, 2008) also proposed to use fuzzy item response theory to add personalization to the tutoring systems.

An example of such a decision tree is presented in Figure 3. 


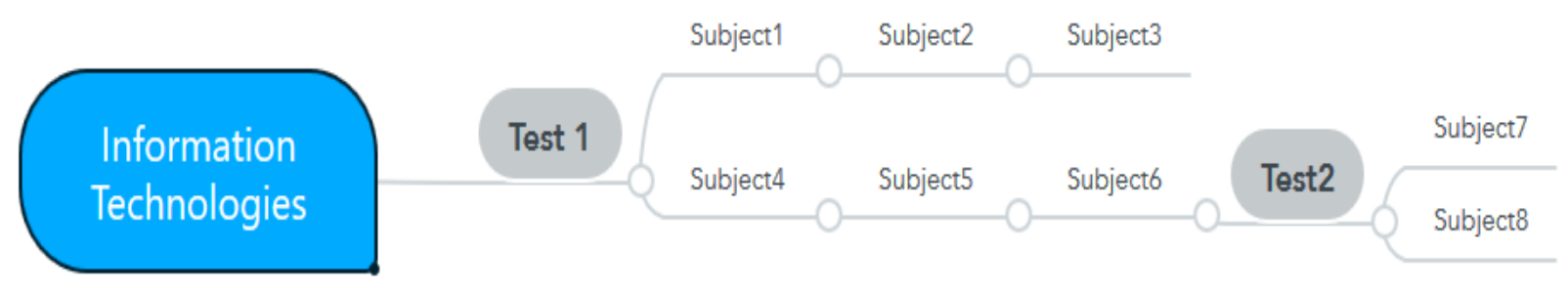

\section{Figure 3. An example of the decision tree}

The probability models presented in the work of V. Serebrovsky (Serebrovsky et al., 2013) allow us to represent the process of distance learning as a dynamic probability system. The set of states, the continuous changing of these states, as well as a defined probability of transitions between these states, allows you to dynamically generate individual paths for students based on various metrics.

Chen C. (Chen, 2008) proposes to use genetics algorithms within ontology graphs to personalize the education of the Chinese language.

The graph model, according to the work of A. Glushchenko, V. Lyubchenko (Glushchenko, 2009; Lyubchenko, Shinkaryuk, 2011) also allows you to take into account the characteristics of the student, student's knowledge, as well as student's ability to learn. The development of an individual path is reduced to the formation of many possible options for further actions. For example, a system may suggest repeating knowledge of some subjects. As a result, a non-linear graph for studying online courses and their subjects is formed. Formally, the model can be represented in the following form (2):

$$
G=\left\langle N, E, S,\left\{p_{i}^{k}\right\},\{s(k)\}, f(i, j)>\right.
$$

where $G$ - graph, $N$ - the set of nodes (course materials), $N$ - the set of edges between nodes, $S$ the set of metrics, $\left\{p_{i}^{k}\right\}$ - probability matrix, $\{s(k)\}$ - the set of metrics values of $k$-th student, $f(i)$ - a functions which can be used to determine probability of movement between $i$-th and $j$-th nodes.

The graph model is the most difficult to implement. Such graphs of knowledge concepts and training subjects also allow us to build roadmaps, which can be used to enhance student skills. An example of a roadmap is shown in Figure 4.

The graph model also has some disadvantages. For example, the evaluation method of students that is used to calculate metrics values may not be indicated. The graph model is also not adapted for the 
skill-based approach. The issue of relevance and importance of the course subjects and materials is not considered. Existing roadmaps, although often take into account market dynamics, are designed for a wide audience and are not personalized.

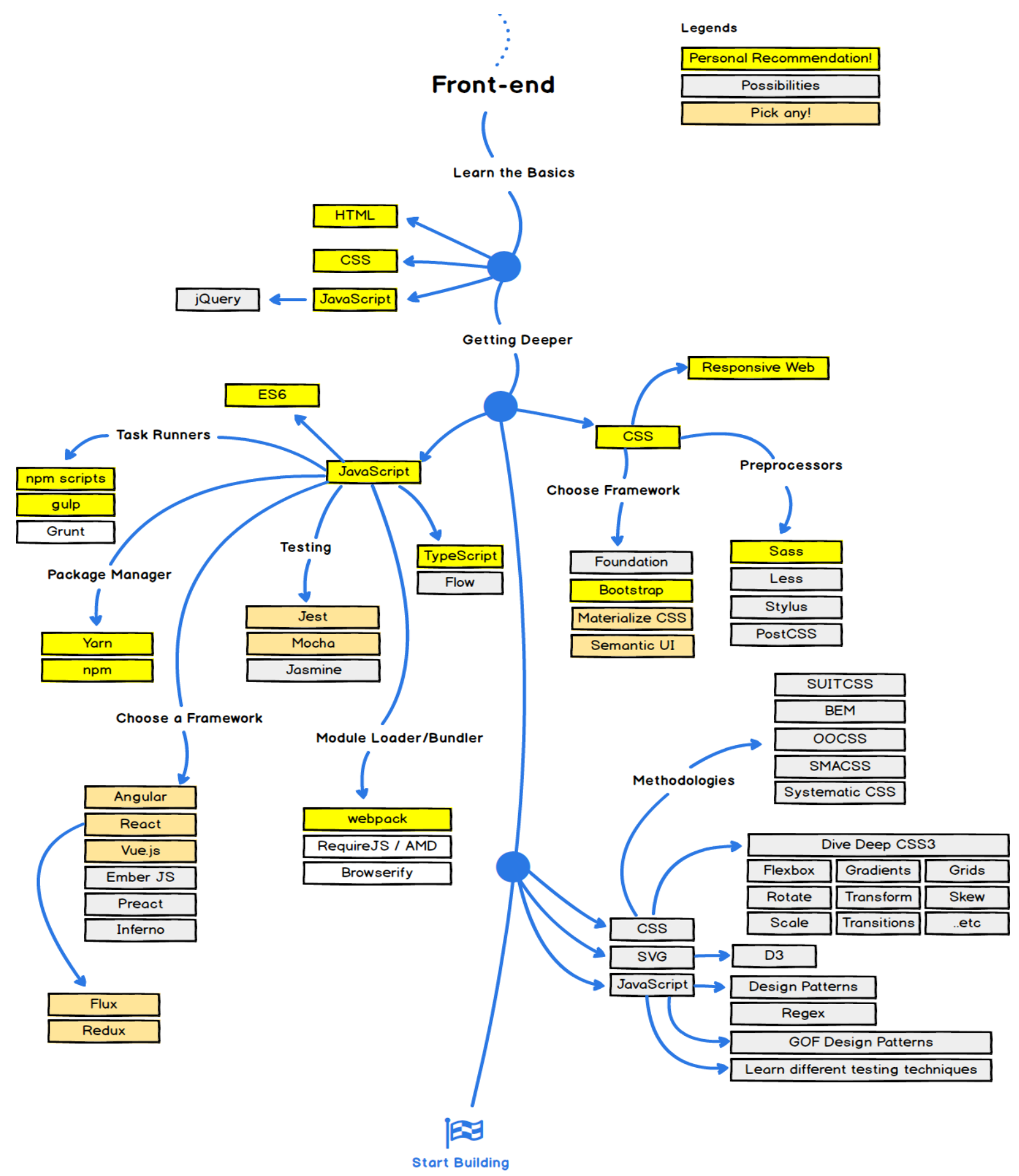

Figure 4. An example of the skill roadmap built with graph model and personal recommendations

Building a knowledge graph and a graph of educational materials also allows you to form roadmaps for the development of a specialist. It is also important to note that employers can also benefit from training in appropriate skills that are relevant to the employer's requests. 


\section{Individual Intelligent Ecosystems}

Modern models of constructing an individual educational path use machine learning algorithms, for example, clustering, help build feedback between the teacher and the student, and build a personalized way of studying subjects depending on knowledge and the ability to acquire knowledge. However, all this may already not be enough to be an effective expert in our world:

- A lot of material comes out in the form of articles, video tutorials, presentations, books and remains separate from the modern educational system;

- It is not optimal to learn subjects of only one course since a large number of courses are developed within the same subject area and are connected;

- The models currently developed don't use the student's skills, as well as those skills that would be of interest to the student;

- Also, this model isn't ready for employers' requests for professionals with certain skills (for solving current and future business tasks).

Based on this, there is a need to improve and expand the model of individual educational paths. As an addition and improvement, the concept of an individual educational ecosystem is proposed.

The structure of this concept is presented in Figure 5.

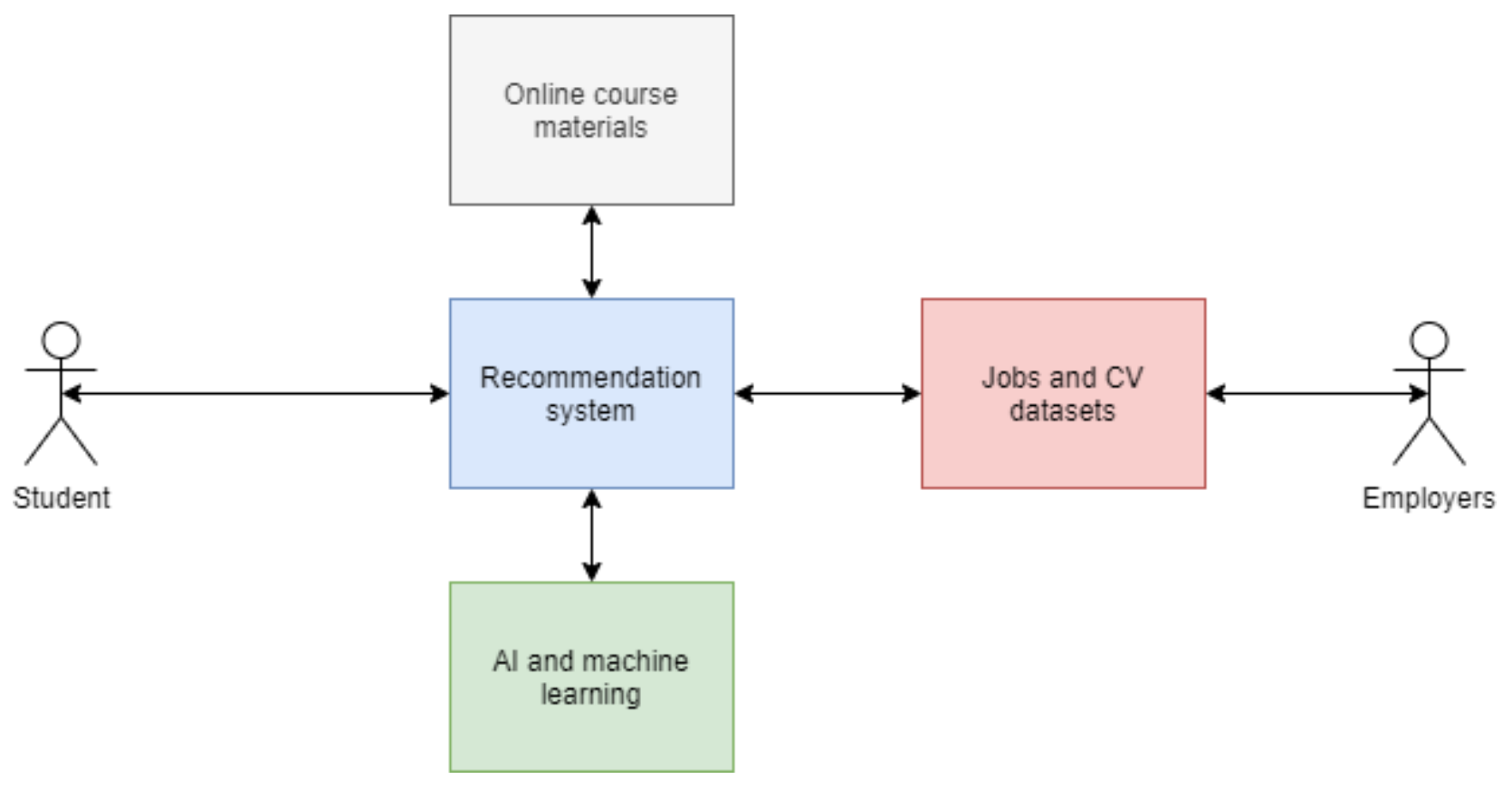

Figure 5. The structure of the concept of the individual education ecosystem

This concept uses the following materials as objects for recommendations: 
- Subjects of distance learning courses;

- Materials of full-time education programs, such as elective subjects;

- Scientific materials, articles, publications;

- Publications in other types of literature, books, online articles;

- Video tutorials;

- Presentations at conferences, forums, webinars, etc.

This model also uses the following characteristics to build personalized recommendations:

- Skills that student possesses;

- Skills that student would like to achieve;

- Skills requested by numerous companies and jobs;

- Dynamics of changes in the popularity of certain skills;

- Cognitive abilities of a student;

- Demand, relevance, and importance of objects for recommendations and others.

To build such recommendations, the use of modern methods of machine learning and artificial intelligence is proposed.

\section{Conclusion}

All in all, the proposed concept of an individual educational ecosystem will make it possible to create such personalized learning paths that will meet both student requests and employers' requirements, as well as allow using the maximum possible number of information sources for developing student skills and knowledge.

In further works, architectures, mathematical methods and methods of constructing this model will be studied, the data collected for its training, the formation of metrics and evaluation functions will be described, and experimental research and comparison of various machine learning methods will be carried out to make the most effective implementation of the concept of an individual educational ecosystem.

\section{References}

Afanasyev, A.N., Voight, N.N. (2013). Prediction of an individual learning path based on a student model with fuzzy characteristics in automated learning systems. Vestnik of the Ulyanovsk State Technical University, 4(64), 58-61. 
Belyaev, R.V., Kravets, O.Y. (2011). Automation of adaptive management of learning paths. Vestnik VSTU, 7. Retrieved from: https://cyberleninka.ru/article/n/avtomatizatsiyaadaptivnogo-upravleniya-traektoriyami-obucheniya

Chen, C. (2008). Intelligent web-based learning system with personalized learning path guidance. Computers \& Education, 51(2), 787-814.

Chen, C., Duh, L. (2008). Personalized web-based tutoring system based on fuzzy item response theory. Expert Systems with Applications, 34(4), 2298-2315.

Glushchenko, A.I. (2009). Development of a method for adaptive learning management along an individual educational path: abstract of candidate dissertation. Moscow.

Hsu, M. (2008). A personalized English learning recommender system for ESL students. Expert Systems with Applications, 34(1), 683-688.

Kravets, O.Y., Zaslavskaya, O.Y. (2012). Competence paradigm for constructing an individual educational path based on feedback in a learning management system. New University, 2(11), 3-11.

Lin, C., Yeh, Y., Hung, Y., Chang, R. (2013). Data mining for providing a personalized learning path in creativity: An application of decision trees. Computers \& Education, 68, 199-210.

Lyubchenko, V.V., Shinkaryuk, O.S. (2011). A method of constructing a learning path in the conditions of mobile learning. Vestnik of the National Technical University "Kharkiv Polytechnic Institute": collection of scientific papers. Thematic Issue: Informatics and Modeling, 17, 81-85.

Serebrovsky, V.V., Tkachenko, A.V., Tkachenko, A.I. (2013). Innovative technologies in education: training using an individual path. Proceedings of the Southwestern State University, 1(46), 26-31.

Soldatkin, E.V. (2013). The algorithm for the formation of the curriculum based on the composition of fuzzy sets. Cloud of science, 3. Retrieved from: https://cyberleninka.ru/article/n/algoritmformirovaniya-uchebnoy-programmy-na-osnove-kompozitsii-nechetkih-mnozhestv 